\title{
Pengaruh Budaya Organisasi dan Organizational Citizenship Behavior (OCB) terhadap Kinerja Pegawai Rumah Sakit Tk. III Baladhika Husada Jember
}

\author{
Desy Khoirun Nisa $^{1 *}$, Budi Santoso ${ }^{2}$, M.Naely Azhad ${ }^{3}$ \\ ${ }^{1}$ Program Studi Manajemen, Fakultas Ekonomi, Universitas Muhammadiyah Jember
}

\author{
A R T I C L E I N F 0 \\ Article history: \\ Received 19 May 2018 \\ Received in revised form \\ 10 June 2018 \\ Accepted 12 July 2018 \\ Available online 27 August \\ 2018 \\ Kata Kunci: \\ budaya organisasi, \\ organizational citizenship \\ behavior (OCB), dan \\ kinerja pegawai \\ Keywords: \\ organizational cultural, \\ organizational citizenship \\ behavior (OCB), and \\ work performance
}

\begin{abstract}
A B S T R A K
Penelitian ini bertujuan untuk menganalisis pengaruh budaya organisasi dan organizational citizenship behavior (OCB) terhadap kinerja pegawai pada Rumah Sakit Tk. III Baladhika Husada Jember. Data yang digunakan dalam penelitian ini berupa data primer yang diperoleh melalui penyebaran kuesioner. Populasi dalam penelitian ini adalah seluruh pegawai di Rumah Sakit Tk. III Baladhika Husada Jember yang berjumlah 98 orang, meliputi dokter, perawat, serta administrasi dan SDM. Penentuan sampel menggunakan studi populasi. Analisis data menggunakan analisis regresi linier berganda. Berdasarkan hasil pengujian hipotesis dapat dinyatakan bahwa budaya organisasi berpengaruh terhadap kinerja pegawai pada Rumah Sakit Tk. III Baladhika Husada Jember atau Ha1 diterima. Organizational Citizenship Behavior berpengaruh terhadap kinerja pegawai pada Rumah Sakit Tk. III Baladhika Husada Jember atau Ha2 diterima.
\end{abstract}

\section{A B S T R A C T}

This research aim to analyze the effect of organizational cultural and organizational citizenship behavior (OCB) to work performance at Baladhika Husada Jember 3rd Level Hospital. Data used in this research is primary data was collected by questionnaire. The population of this research is all employee of Baladhika Husada Jember 3rd Level Hospital amount of 98 peoples, included doctor, nurse, also administration and human resources. Determination of samples using total sampling. The analyze technique used multiple linier regressions analysis. The result of hypothesis testing shown that the organizational cultural has significant effect to work performance at Baladhika Husada Jember 3rd Level Hospital or H1 accepted. Organizational citizenship behavior (OCB) has significant effect to work performance at Baladhika Husada Jember 3rd Level Hospital or H2 accepted.

\footnotetext{
* Corresponding author.

E-mail addresses: desy.khoirun@gmail.com (Desy Khoirun Nisa)
} 


\section{Pendahuluan}

OCB merupakan perilaku sosial yang positif yang dilakukan oleh karyawan dengan memberikan kontribusi pada organisasi dan lingkungan kerjanya yang melebihi tuntutan peran atau posisi dalam bekerja. Perilaku ini dapat disebut sebagai perilaku extra-role atau good citizen yang merupakan makhluk sosial dengan mengutamakan kepentingan umum daripada kepentingan pribadi. Selanjutnya Organ (1988) dalam Robbins dan Judge (2013) mengukur OCB dengan lima dimensi yang dapat meningkatkan kinerja karyawan, yaitu (a) altruism (perilaku membantu orang lain); (b) conscientiousness (ketelitian dan kehati-hatian); (c) sportsmanship (perilaku yang sportif); (d) courtesy (menjaga hubungan baik); (e) civic virtue (kebijaksanaan warga), bahwa OCB memiliki peranan untuk meningkatkan kinerja. Borman dan Motowidlo dalam Novliadi (2007) pernah mengatakan bahwa OCB dapat meningkatkan kinerja organisasi karena perilaku ini merupakan pelumas dari mesin sosial dalam organisasi,dengan kata lain dengan adanya perilaku ini maka interaksi sosial pada anggota anggotaorganisasi menjadi lancar mengurangi terjadinya perselisihan, dan meningkatkan efisiensi. Jika tiap individu memiliki OCB di dalam dirinya maka organisasi yang mereka naungipun akan menunjukkan tingkat kinerja organisasi yang tinggi.

Penelitian dengan tema sejenis, pernah dilakukan oleh Maulani, dkk (2015), Dharmayanthi dan Dewi (2016), Kalsum, dkk (2017), serta Putri dan Utami (2017). Maulani, dkk (2015), Santoso (2017) melakukan penelitian tentang OCB. Hasil penelitiannya menyatakan bahwa budaya organisasi dan komitmen organisasi berpengaruh terhadap OCB dan kinerja karyawan. OCB berpengaruh terhadap kinerja karyawan. Dharmayanthi dan Dewi (2016) melakukan penelitian mengenai pengaruh kecerdasan emosional, komitmen organisasi, dan organizational citizenship behavior (OCB) terhadap kinerja pegawai Fakultas Ekonomi dan Bisnis Universitas Udayana. Hasil penelitian menyatakan bahwa kecerdasan emosional, komitmen organisasi, dan OCB berpengaruh positif dan signifikan terhadap kinerja pegawai. Kalsum, dkk (2017) melakukan penelitian dengan tujuan untuk mengetahui pengaruh budaya organisasi terhadap kinerja perawat di ruang rawat inap RSU Bahteramas Provinsi Sulawesi Tenggara. Hasil penelitian menyatakan bahwa budaya organisasi berpengaruh terhadap kinerja perawat.

Hasil penelitian Maulani, dkk (2015) menyatakan bahwa budaya organisasi dan OCB berpengaruh terhadap kinerja karyawan. Hasil peneltiian Kalsum, dkk (2017) menyatakan budaya organisasi berpengaruh terhadap kinerja perawat. Hasil penelitian Dharmayanthi dan Dewi (2016) menyatakan OCB berpengaruh terhadap kinerja pegawai. Penelitian ini merupakan replikasi dari penelitian tersebut dan dilakukan pada objek yang berbeda yaitu Rumah Sakit Tk. III Baladhika Husada Jember. Hal ini dilakukan untuk menguji konsistensi pengaruh budaya organisasi dan OCB berpengaruh terhadap kinerja karyawan.

Rumah Sakit Tk. III Baladhika Husada Jember adalah rumah sakit negeri kelas III, yang berlokasi di Jl PB Sudirman Jember merupakan salah satu Rumah Sakit TNI AD, dalam pelayanannya rumah sakit ini tidak hanya melayani TNI AD saja tetapi juga bagian dari fasilitas medis masyarakat Jember, dan masyarakat mengenalnya dengan Rumah Sakit DKT Jember. Sebagai perusahaan pelayanan jasa, rumah sakit menghasilkan produk yang bersifat tidak berwujud atau intangible, maka SDM merupakan unsur yang sangat penting baik dalam produksi maupun penyampaian jasa dalam pelayanan berkualitas di rumah sakit. Dengan keadaan seperti ini maka karyawan Rumah Sakit Tk. III Baladhika Husada Jember sangat dituntut untuk melakukan pekerjaan ekstra diluar job describtionnya. Misalnya dengan sukarela bekerja tambahan diluar jam kerja, membantu rekan sekerjanya untuk mempercepat pekerjaan dalam memberikan pelayanan, membentuk tim kerja yang solid, menciptakan rasa solidaritas yang tinggi antar sesama karyawan dan sebagainya. Perilaku yang demikian akan sangat mendukung peningkatan keefektifan dan kelangsungan hidup organisasi dalam mencapai tujuan atau sasaran organisasi.

Pegawai yang bertugas di Rumah Sakit Tk. III Baladhika Husada Jember memang dituntut untuk menjalankan tugas dan tanggungjawabnya dengan sangat baik. Pelayanan prima merupakan tuntutan yang senantiasa harus dijunjung tinggi oleh seluruh karyawan Rumah Sakit Tk. III Baladhika Husada Jember guna tercapainya sasaran organisasi. Tuntutan kerja yang tinggi tentunya terkadang membuat setiap pegawai merasakan jenuh dan tidak maksimal dalam menjalankan tugasnya sehingga pegawai akan mengalami penurunan kinerja. Budaya dapat tercermin dari kinerja para perawat pelaksana di Rumah Sakit Tk. III Baladhika Husada Jember. Perawat di rumah sakit tersebut dituntut untuk bekerja sesuai dengan visi dan misi instansi keperawatan, yang tercakup dalam penuntun perilaku pelayanan PEDULI (Profesional, Empati, Dedikasi, Universal, Loyal dan Inisiatif). Visi dan misi ini mencerminkan budaya dalam rumah sakit dan para perawat harus menginternalisasi visi tersebut di dalam memberikan pelayanan kepada para pasien, sehingga akan membentuk kinerja yang memuaskan. Berdasarkan hasil wawancara dengan Divisi Pelayanan Medis Rumah Sakit Tk. III Baladhika Husada Jember pada pra survey diperoleh informasi bahwa kinerja perawat Rumah Sakit Tk. III Baladhika Husada Jember dinilai masih belum optimal. Berbagai permasalahan mengenai aspek budaya organisasi dan Organizational Citizenship Behavior (OCB), tentunya akan mempengaruhi kinerja pegawai yang pada akhirnya akan berdampak 
terhadap pencapain kinerja organisasi secara keseluruhan. Berdasarkan pemikiran tersebut, penelitian ini akan mengkaji pengaruh budaya organisasi dan organizational citizenship behavior (OCB) terhadap kinerja pegawai (Studi pada Rumah Sakit Tk. III Baladhika Husada Jember).

Robbins dan Judge (2013) mendefinisikan Organizational Citizenship Behavior sebagai perilaku pilihan yang tidak menjadi bagian dari kewajiban kerja formal seorang karyawan, namun mendukung berfungsinya organisasi tersebut secara efektif. Sedangkan, Yukl (2013) menjelaskan bahwa Organizational Citizenship Behavior merupakan perilaku sukarela dari seorang pekerja untuk mau melakukan tugas atau pekerjaan di luar tanggung jawab atau kewajibannya demi kemajuan atau keuntungan organisasinya. Menurut Podsakoff et al (2000) mendefinisikan Organizational Citizenship Behavior sebagai perilaku sukarela, perilaku melebihi tuntutan tugas yang berkontribusi terhadap kesuksesan organisasi.

Menurut Organ dan Konovsky (Sahrah, 2010), Organizational Citizenship Behavior (OCB) adalah perilaku prososial atau tindakan ekstra yang melebihi deskripsi peran yang ditetapkan suatu organisasi. Sedangkan menurut Triyanto dan Santosa (2009) Organizational Citizenship Behavior (OCB) adalah suatu perilaku sukarela yang tampak dan dapat diamati yang didasari oleh suatu motif/nilai yang dominan. OCB merupakan suatu perilaku sukarela yang tampak dan dapat diamati, dimana didasari oleh suatu motif atau nilai yang dominan juga dapat didasarkan pada reward dan punishment yang bersifat eksternal yang diberikan oleh perusahaan (Triyanto dan Santosa, 2009).

Dari berbagi pendapat para ahli mengenai Organizational Citizenship Behavior atau disebut juga perilaku kewargaorganisasian, maka dapat disimpulkan bahwa Organizational Citizenship Behavior atau perilaku kewargaorganisasian adalah perilaku yang secara sadar dan sukarela dilakukan diluar job discription secara formal dan apabila itu tidak dilakukanpun tidak akan mendapatkan sanksi.

\section{Pengembangan Hipotesa}

Berdasarkan teori serta temuan empiris diatas, dapat disusun hipotesis penelitian sebagai berikut: Ha1 : Budaya organisasi berpengaruh terhadap kinerja pegawai pada Rumah Sakit Tk. III Baladhika Husada Jember.

Ha2 : Organizational citizenship behavior (OCB) berpengaruh terhadap kinerja pegawai pada Rumah Sakit Tk. III Baladhika Husada Jember.

\section{Metode}

Populasi dari penelitian ini adalah seluruh pegawai di Rumah Sakit Tk. III Baladhika Husada Jember yang berjumlah 98 orang, meliputi dokter, perawat, serta administrasi dan SDM. Mengacu pada pendapat Arikunto (2006) yang mengemukakan: "Apabila seseorang ingin meneliti semua elemen yang ada dalam wilayah penelitian, maka penelitiannya merupakan penelitian populasi atau penelitiannya juga disebut studi populasi atau studi sensus". Dari pengertian tersebut, maka penelitian ini merupakan penelitian populasi yaitu meneliti seluruh populasi yang ada meliputi dokter, perawat, serta administrasi dan SDM di PT Rumah Sakit Tk. III Baladhika Husada Jember sebanyak 98 orang.

\section{Hasil dan Pembahasan}

\section{Hasil Analisis Regresi Linier Berganda}

Berdasarkan pengujian dengan bantuan program SPSS for Windows 17.0 diperoleh hasil yang dapat disajikan dalam Tabel 4.8 .

Tabel 1. Hasil Perhitungan Regresi Linear Berganda Variabel Koef. Regresi thitung Sig. Keterangan

\begin{tabular}{lclcc}
\hline \multicolumn{1}{c}{ Variabel } & Koef. Regresi & $\mathbf{t}_{\text {hitung }}$ & Sig. & Keterangan \\
\hline Konstanta & 4,259 & 3,392 & 0,001 & - \\
X1 & 0,275 & 5,322 & 0,000 & Signifikan \\
X2 & 0,458 & 6,341 & 0,000 & Signifikan \\
\hline \multirow{3}{*}{ R } & & 0,776 \\
& R Square & 0,603 \\
& F hitung & 72,078 \\
& Sig & 0,000 \\
& & $\mathrm{~N}$ & 98 \\
\hline
\end{tabular}

Sumber: Lampiran 6 


\section{Hasil Uji t}

Hasil perhitungan uji t dengan menggunakan program SPSS for Windows dapat dilihat pada Tabel 1. Berdasarkan tabel tersebut dapat diketahui besarnya pengaruh masing-masing variabel bebas terhadap variabel terikat sebagai berikut: 1. Pengaruh variabel budaya organisasi (X1) terhadap kinerja pegawai $(\mathrm{Y})$

1. Berdasarkan Tabel 4.8 dapat diketahui bahwa signifikansi variabel budaya organisasi $<\alpha$ yaitu $0,000<0,05$. Karena tingkat probabilitasnya lebih kecil dari 5\%, maka H0 ditolak, berarti secara parsial variabel budaya organisasi (X1) mempunyai pengaruh signifikan terhadap kinerja pegawai pada Rumah Sakit Tk. III Baladhika Husada Jember (Y). Sehingga, hipotesis yang menyatakan bahwa budaya organisasi berpengaruh terhadap kinerja pegawai pada Rumah Sakit Tk. III Baladhika Husada Jember terbukti kebenarannya atau Ha1 diterima.

2. Pengaruh variabel Organizational Citizenship Behavior (X2) terhadap kinerja pegawai (Y). Berdasarkan Tabel 4.8 dapat diketahui bahwa signifikansi Organizational Citizenship Behavior $<\alpha$ yaitu $0,000<0,05$. Karena tingkat probabilitasnya lebih kecil dari 5\%, maka H0 ditolak, berarti secara parsial variable Organizational Citizenship Behavior (X2) mempunyai pengaruh signifikan terhadap kinerja pegawai pada Rumah Sakit Tk. III Baladhika Husada Jember (Y). Sehingga, hipotesis yang menyatakan bahwa Organizational Citizenship Behavior (OCB) berpengaruh terhadap kinerja pegawai pada Rumah Sakit Tk. III Baladhika Husada Jember terbukti kebenarannya atau Ha2 diterima.

\section{Pembahasan}

\section{Pengaruh Budaya organisasi terhadap Kinerja Pegawai}

Hasil uji regresi menunjukkan variabel budaya organisasi berpengaruh positif dan signifikan terhadap kinerja pegawai dengan koefisien 0,275 . Hal ini berarti faktor budaya organisasi yang diukur melalui pegawai menciptakan ide-ide yang inovatif dalam pekerjaan, pegawai memperhatikan segala ketetapan, analisis, dan memperhatikan lebih detail terhadap hal-hal di sekitar pekerjaan, pegawai selalu fokus kepada hasil kerja daripada teknik dan proses yang digunakan, pegawai cukup memperhitungkan pengaruh hasil-hasil terhadap karyawan dalam organisasi, pegawai cukup memiliki kemampuan bekerjasama dalam tim, pegawai sebagai anggota organisasi cukup tertantang untuk bekerja dengan kompetitif, dan pegawai sebagai anggota organisasi cukup dituntut untuk terus tumbuh dan berkembang merupakan suatu faktor yang menentukan kinerja pegawai pada Rumah Sakit Tk. III Baladhika Husada Jember.

Budaya organisasi adalah makna bersama yang meliputi sikap, nilai dan keyakinan karyawan terhadap apa yang berlaku dalam organisasi. Sutrisno (2013), budaya organisasi merupakan suatu kekuatan sosial yang tidak tampak, yang dapat menggerakkan orang-orang dalam suatu organisasi untuk melakukan aktivitas kerja. Budaya organisasi yang benar-benar dikelola sebagai alat manajemen akan berpengaruh dan menjadi pendorong bagi karyawan untuk berperilaku positif, dedikatif, dan produktif. Dimana budaya organisasi yang kuat atau positif akan mempengaruhi kinerja organisasi tersebut sehingga mendukung tujuan-tujuan perusahaan, sebaliknya yang lemah atau negatif akan berdampak buruk terhadap pencapaian tujuan suatu organisasi.

Robbins (2008) membagi Budaya Organisasi dalam dua katagori yaitu budaya kuat dan budaya lemah. Masing-masing katagori budaya organisasi tersebut akan memanifestasikan derajat pengaruh yang berbeda-beda terhadap proses kognitif dimana karyawan mengintepretasikan lingkungan mereka. Semakin kuat budaya semakin kuat pula pengaruhnya terhadap lingkungan dan perilaku karyawan. Karena budaya yang kuat akan menciptakan rasa memiliki danvmeningkatkan kinerja. Sebaliknya semakin lemah budaya, semakin lemah pulavpengaruhnya terhadap lingkungan dan perilaku karyawan (Ndara, 2003). Menurut Ndara (2003) salah satu cara yang efektif untuk menciptakan dan internalisasi budaya organisasi adalah melalui pelatihan karyawan. Pelatihan berguna untuk membagi pengetahuan, ketrampilan dan kemampuan, mengkomunikasikan nilai

dan perilaku yang diharapkan untuk mencapai tujuan organisasi, sehingga akan tercapai persepsi bersama yang konsisten mengenai apa yang diharapkan.

Budaya organisasi cenderung berhubungan dengan nilai-nilai atau norma-norma yang ada di organisasi kerja. Jika dalam organisasi tersebut berkembang suatu budaya kerja yang positif, maka hal tersebut akan menguntungkan aktivitas organisasinya. Keuntungan tersebut dapat terlihat dari hasil kerja anggota organisasi tersebut yang memenuhi standar kerja yang ditetapkan organisasi. Hal ini sejalan dengan yang dikemukakan oleh Robbins dan Judge (2008) yang mengkaitkan bahwa didalam budaya kerja yang kuat terkandung karakteristik bahwa budaya organisasi tersebut berorientasi pada hasil kerja (kinerja) karyawannya. Hasil penelitian ini sesuai dengan hasil penelitian Maulani, dkk (2015) serta Kalsum, dkk (2017) yang juga menemukan bukti bahwa budaya organisasi berpengaruh terhadap kinerja pegawai. 


\section{Pengaruh Organizational Citizenship Behavior terhadap Kinerja Pegawai}

Hasil uji regresi menunjukkan variabel Organizational Citizenship Behavior berpengaruh positif dan signifikan terhadap kinerja pegawai dengan koefisien 0,458. Hal ini berarti faktor Organizational Citizenship Behavior yang diukur melalui pegawai cukup bersedia untuk membantu rekan kerja dalam menyelesaikan pekerjannya, pegawai merasa berkewajiban membantu teman kerja untuk mencegah timbulnya masalah sehubungan dengan pekerjannya dengan cara memberi konsultasi dan informasi, pegawai lebih suka memfokuskan pada sisi positif atas apa yang salah dalam pekerjaan daripada membahas siapa yang salah, pegawai akan membantu mencari ide-ide baru untuk meningkatkan produktivitas dalam perusahaan, dan pegawai bersedia dengan sungguh-sungguh mengukuti peraturanperaturan dan prosedur dalam bekerja merupakan suatu faktor yang menentukan kinerja pegawai pada Rumah Sakit Tk. III Baladhika Husada Jember.

Organizational Citizenship Behavior (OCB) lebih berkaitan dengan manifestasi seseorang (karyawan) sebagai mahluk sosial. OCB merupakan bentuk kegiatan sukarela dari anggota organisasi yang mendukung fungsi organisasi sehingga perilaku ini lebih bersifat altruistic (menolong) yang diekspresikan dalam bentuk tindakan tindakan yang menunjukkan sikap tidak mementingkan diri-sendiri dan perhatian pada kesejahteraan orang lain (Muhdar, 2015). Menurut Smith, et. al, (2004) OCB adalah perilaku karyawan berupa kerelaan mengerjakan tugas-tugas melebihi tugas pokoknya. Karyawan memiliki kebebasan untuk bertindak dan tidak memperoleh reward, dalam konteks struktur reward formal dari organisasi, atas perilakunya tersebut. OCB merupakan tindakan social secara kolektif dalam konteks budaya berbudi luhur dalam rangka meningkatkan kinerja organisasi sehingga mampu menghasilkan outcome pelayanan prima dalam sebuah organisasi ( Santoso, 2017).

Aset kunci yang sangat penting untuk pengembangan dan pencapaian tujuan organisasi, atau perusahaan adalah sumber daya manusia. Organisasi yang sukses membutuhkan karyawan yang akan melakukan lebih dari sekedar tugas formal mereka dan mau memberikan kinerja yang melebihi harapan. Organisasi menginginkan karyawan yang bersedia melakukan tugas yang tidak tercantum dalam deskripsi pekerjaan mereka (Triyanto, 2009). Robbins dan Judge (2008) mengemukakan fakta yang menunjukkan bahwa organisasi yang mempunyai karyawan yang memiliki OCB (Organizational Citizenship Behavior) yang baik, akan memiliki kinerja yang lebih baik dari organisasi lain. Perilaku positif karyawan akan mampu mendukung kinerja individu dan kinerja organisasi untuk perkembangan organisasi yang lebih baik (Winardi, 2012). Penelitian Rastgaret et al (2012), menjelaskan bahwa ketika karyawan terlibat dalam perilaku ekstra peran, kinerja mereka akan meningkat, karyawan akan melakukan lebih dari tugas resmi oleh setiap individu, ketika karyawan berusaha lebih keras dari sebelumnya extra peran behavior, prestasi kerja juga akan meningkat. Hasil penelitian ini sesuai dan mendukung hasil penelitian Maulani, dkk (2015), Dharmayanthi dan Dewi (2016), serta Putri dan Utami (2017) yang menyatakan bahwa Organizational Citizenship Behavior (OCB) berpengaruh terhadap kinerja pegawai.

\section{Simpulan dan saran}

Berdasarkan uraian-uraian yang telah diungkapkan pada pembahasan, maka dapat diambil beberapa kesimpulan sebagai jawaban atas pokok permasalahan yang diajukan dalam penelitian ini. Pertama, budaya organisasi berpengaruh terhadap kinerja Pegawai di Rumah Sakit Tk. III Baladhika Husada Jember dengan koefisien regresi sebesar 0,275. Sehingga, hipotesis yang menyatakan bahwa budaya organisasi berpengaruh terhadap kinerja pegawai pada Rumah Sakit Tk. III Baladhika Husada Jember terbukti kebenarannya atau Ha1 diterima. Dan kedua, Organizational Citizenship Behavior berpengaruh terhadapkinerja Pegawai di Rumah Sakit Tk. III Baladhika Husada Jember dengan koefisien regresi sebesar 0,458. Sehingga, hipotesis yang menyatakan bahwa Organizational Citizenship Behavior berpengaruh terhadap kinerja pegawai pada Rumah Sakit Tk. III Baladhika Husada Jember terbukti kebenarannya atau Ha2 diterima.

\section{Daftar Rujukan}

Arikunto, Suharsimi. 2006. Prosedur Penelitian Suatu Pendekatan Praktek. Jakarta: PT Rineka Cipta.

Dermawan, Didit. 2013. Prinsip-prinsip Perilaku Organisasi. Surabaya: Pena. Semesta.

Dharmayanthi, Anak Agung Inten PS dan Anak Agung Sagung Kartika Dewi. 2016. Pengaruh Kecerdasan Emosional, Komitmen Organisasi, Dan Organizational Citizenship Behavior terhadap Kinerja Pegawai FEB. EJurnal Manajemen Unud, Vol. 5, No. 2, 2016. 
Indriantoro, Nur dan Bambang Supomo, 2009. Metodologi Penelitian Bisnis untuk Akuntansi dan. Manajemen. Yogyakarta: BPFE Yogyakarta.

Kalsum, Umi, La Ode Ali Imran Ahmad dan Wa Ode Sitti Nurzalmariah Andisiri. 2017. Pengaruh Budaya Organisasi terhadap Kinerja Perawat Pelaksana di Ruang Rawat Inap Rumah Sakit Umum Bahteramas Provinsi Sulawesi Tenggara Tahun 2016. Jurnal Ilmiah Mahasiswa Kesehatan MasyarakatVol. 2 No.6 Mei 2017.

Koesmono, H. Teman. 2005. Pengaruh Budaya Organisasi terhadap Motivasi dan Kepuasan Kerja serta Kinerja Karyawan Pada Sub Sektor Industri. Pengolahan Kayu Skala Menengah di Jawa Timur. Jurnal manajemen. \& kewirausahaan, Vol. 7, No. 2, September 2005: 171-188.

Kreitner, Robert \& Angelo Kinicki. 2005. Perilaku Organisasi 2 (Edisi 5). Jakarta: Salemba Empat.

Mangkunegara, Anwar Prabu. 2007. Evaluasi Kinerja Sumber Daya Manusia. Jakarta: Refika Aditama.

Maulani, Venty Hertina, Widiartanto Widiartanto, dan Reni Shinta Dewi. 2015. Pengaruh Budaya Organisasi dan Komitmen Organisasi terhadap Kinerja Karyawan melalui Organizational Citizenship Behavior (OCB) sebagai Variabel Intervening (Studi Kasus pada Karyawan PT Masscom Graphy Semarang). Jurnal Ilmu Administrasi Bisnis Volume 4, Nomor 3, Tahun 2015.

Ndara, Taliziduhu. 2003. Kybernolody Ilmu pemerintahan Baru, Jakarta: PT. Rinaka Cipta.

Podsakoff, P. M., S. B. MacKenzie, J. B. Paine, \& D. G. Bachrach. 2000. Organizational Citizenship Behavior: A Critical Review of the Theoretical and Empirical Literature and Suggestion for the Future Research. Journal of Management Vol. 26, no. 3, 2000.

Rashid, Abdul M. Z., M. Sambasivan \& J. Johari (2003). The influence of Corporate Culture and Organizational Commitment on Performance.Journal of Management Development. Vol. 22, No. 8, pp. 708-728.

Rivai, Veithzal dan Basri, A. F. M. 2005. Performance appraisal. Jakarta: PT.Raja. Grafindo Persada.

Rivai, Veitzal. 2009. Manajemen Sumber Daya Manusia Untuk Perusahaan :Dari teori ke Praktik. Edisi Pertama Cetakan Ketiga. Jakarta : PT. Raja Grafindo Persada.

Riyadi, Sugeng. 2007. Keperawatan Kesehatan Masyarakat. Jakarta: Salemba Medika.

Robbins, S. P. 2008. Perilaku Organisasi: Konsep, Kontroversi, dan Aplikasi. Alih Bahasa Handayana Pujaatmika. Edisi Bahasa Indonesia. Jakarta: Prenhalindo.

Robbins, Stephen P \& Judge, Timothy A. 2013. Organizational Behavior Edition. 15. New Jersey: Pearson Education.

Sahrah, A. 2010. Organizational Citizenship Behavior Ditinjau dari Kepuasan kerja dan jenis kelamin para perawat rumah sakit. Jurnal Psikologi Universitas Mercu Buana Yogyakarta.

Schein, Edgar H. 2011. Organizational Culture and Leadership. Fourth. Edition. San Fransisco: Jossey-Bass. Smith, C. A., Organ, D. W., Near, J. P. 2004. Organizational Citizenship Behavior: It's Nature and Antecedents. Journal of Applied Psychology Vol 68, 653-663.

Santoso, Budi, 2017, Peranan moral pegawai, komitmen pegawai, motivasi pegawai dan organizational citizenship behavior (OCB) pegawai terhadap quality service (Studi Lembaga Pendidikan Muhamadiyah di Kabupaten Jember), Jurnal manajemen dan Bisnis Indonesia Universitas Muhammadiyah Jember, Vol 3 No.2 Tahun 2017

Sutrisno, Edy. 2013. Manajemen Sumber Daya Manusia, Cetakan Kelima. Yogyakarta: Prenada Media. 
Triyanto, A \& Santosa, C. E. 2009. Organizational Citizenship Behavior (OCB) Dan Pengaruhnya Terhadap Keinginan Keluar dan Kepuasan Kerja Karyawan. Jurnal Manajemen, Vol. 7 No. 4.

Yukl, Gary. 2013. Kepemimpinan Dalam Organisasi. Edisi Kelima. Jakarta: PT Indeks. 